\title{
Multilineage gene expression precedes commitment in the hemopoietic system
}

\author{
Ming Hu, ${ }^{1}$ Diane Krause, ${ }^{2}$ Mel Greaves, ${ }^{1}$ Saul Sharkis, ${ }^{3}$ Michael Dexter, ${ }^{4}$ Clare Heyworth, ${ }^{4}$ and \\ Tariq Enver ${ }^{1,5}$ \\ ${ }^{1}$ The Leukaemia Research Fund Centre at the Institute of Cancer Research, Chester Beatty Laboratories, London, SW3 6JB, \\ $\mathrm{UK}_{j}{ }^{2}$ Department of Laboratory Medicine, Yale University, New Haven, Connecticut 06520 USA; ${ }^{3}$ Johns Hopkins Oncology \\ Center, Baltimore, Maryland 21287 USA; ${ }^{4}$ Paterson Institute for Cancer Research, Christie Hospital, \\ Manchester, M20 9BX, UK
}

We have tested the hypothesis that multipotential hemopoietic stem and progenitor cells prime several different lineage-affiliated programs of gene activity prior to unilineage commitment and differentiation. Using single cell RT-PCR we show that erythroid ( $\beta$-globin) and myeloid (myeloperoxidase) gene expression programs can be initiated by the same cell prior to exclusive commitment to the erythroid or granulocytic lineages. Furthermore, the multipotential state is characterized by the coexpression of several lineage-affiliated cytokine receptors. These data support a model of hemopoietic lineage specification in which unilineage commitment is prefaced by a "promiscuous" phase of multilineage locus activation.

[Key Words: Hemopoietic stem cells; lineage specification; cytokine receptors]

Received October 7, 1996; revised version accepted February 11, 1997.

Differentiation of lineage-committed, and therefore more developmentally restricted, precursors from multipotential cells involves the selection and elaboration of appropriate programs of gene expression (Caplan and Ordahl 1978). These programs presumably arise through changes in the functional balance of cellular transcription factors ultimately resulting in the formation of stable active transcription complexes at the regulatory elements of lineage specific gene loci; changes in chromatin structure in the vicinity of these regulatory elements are thought to be an essential feature of this process (Felsenfeld 1992).

The developmental options facing multipotential hemopoietic stem and progenitor cells include quiescence, programmed cell death, proliferation, self-renewal, and differentiation. Because hemopoietic stem cells are pluripotent, supporting the production of at least eight different lineages of mature and functionally distinct blood cells, lineage specification is an implicit feature of the differentiation process but is not yet understood at the molecular level (Lajtha 1979; Metcalf 1989; Cross and Dexter 1991). Addressing this issue requires access to multipotential cells that retain differentiation potential. Because such cells are relatively rare in vivo, most studies of this sort have relied on cellular models of the multipotential stem-cell compartment (Spooncer et al. 1984; Greenberger et al. 1983; Palacios et al. 1987). Factor-dependent cell Paterson (FDCP)-mix cells were de-

${ }^{5}$ Corresponding author.

E-MAIL tariq@icr.ac.uk; FAX (44)-171-352-3299. rived from long-term cultures of murine bone marrow and can be maintained as self-renewing undifferentiated cells by the hemopoietic growth factor interleukin-3 (Spooncer et al. 1986). They appear normal in that they do not have any karyotypic abnormalities and are not leukemogenic in vivo. In addition these cells will undergo multimyeloid differentiation when confronted with appropriate physiological regulators of hemopoiesis such as stromal cells or growth factors. Thus, addition of granulocyte colony stimulating factor (G-CSF) and granulocyte-macrophage colony stimulating factor (GMCSF) elicits the production of granulocytes and monocytes (Heyworth et al. 1990). Similarly, addition of erythropoietin (EPO) results in the production of erythroid cells (Heyworth et al. 1995).

Molecular studies of FDCP-mix and similarly derived cells have revealed the following. The chromatin structure of the $\beta$-globin locus control region (LCR) is in an active configuration, that is, $5^{\prime} \mathrm{HS} 1$ and $5^{\prime} \mathrm{HS} 2$ are nuclease-hypersensitive (Jimenez et al. 1992). Low levels of GATA-1 and EPO-receptor transcription are detectable (Crotta et al. 1990; Heberlein et al. 1992) and structural analysis of the EPO-R gene revealed the presence of a promoter- and intronic-hypersensitive site (Heberlein et al. 1992). These data argue strongly that a variety of erythroid-lineage processes are initiated in multipotential cells prior to the occurrence of an erythroid commitment decision. This phenomenon, often referred to as lineage priming, is not a peculiarity of erythroid lineageaffiliated locus activation but has been documented for at least three other hemopoietic lineages. Both the transcriptional enhancers for the immunoglobulin heavy chain and the CD3 $\delta$ component of the $\mathrm{T}$-cell receptor 
have been shown to be accessible in multipotential cells (Ford et al. 1992a). More recent studies have shown that the major enhancer of the neutrophil-specific myeloperoxidase gene (MPO) is also primed in undifferentiated FDCP-mix cells (Zhu et al. 1994; Ford et al. 1996).

On the basis of data such as these we have argued that under conditions of self-renewal, multipotential progenitor cells simultaneously prime several different lineageaffiliated programs of gene activity. This multilineage priming has also been suggested as underlying the simultaneous expression of multiple lineage markers observed in some mixed-lineage leukemias (Greaves et al. 1986). In such a scheme, unilineage commitment and differentiation involves both the consolidation of appropriate programs of gene activity and also the repression of primed gene programs that are no longer appropriate for differentiation down the lineage pathway selected. The model necessarily assumes that these different lineage programs, for example, both erythroid and granulocytic, are primed by the same individual cell. The data could equally well be explained by positing that the different lineage-affiliated programs are only selectively and/or exclusively primed in specific subpopulations of progenitors that have already made an appropriate commitment step. Understanding the cellular basis or distribution of these different lineage-affiliated programs of gene activity is critical to resolve this issue.

In this study we have examined the transcriptional programs of multipotential cells at the single-cell level. These studies were initially performed in the FDCP-mix model system and key results were confirmed in normal, freshly isolated, multipotential cells identified primarily on the basis of their expression of the stem-cell antigen CD34 (Brown et al. 1991; Krause et al. 1994).

\section{Results}

\section{The cellular model FDCP-mix A4}

The immunophenotype of the FDCP-mix A4 passage used in the experiments reported here is essentially identical to that reported previously for other passages of A4 cells (Ford et al. 1992b; see Materials and Methods). The activation status of a variety of different lineage-affiliated genes was analyzed, initially at the population level, in A4 using RT-PCR (Fig. 1A). RT-PCR was used because although a number of these loci are thought to be primed for activation, actual transcription is generally at quite a low level. Three classes of genes were examined: genes for hemopoietic growth factor receptors, genes for transcription factors, and genes such as globin and MPO, which encode products with lineage-specific effector functions in mature cells. Because interleukin-3 (IL-3) and GM-CSF receptors share a common $\beta$-chain (Miyajima et al. 1993) the expression of these two receptors was analyzed using $\alpha$-chain specific primers. Transcripts for the IL-3 receptor were detected, consistent with the reported role of IL-3 as a mitogenic or survival factor for multipotential hemopoietic cells and also with the dependence of FDCP-mix cells on IL-3 for proliferation and survival (Heyworth et al. 1990). Expression of all the other cytokine receptors analyzed, for example, GMCSF-R, G-CSF-R, c-kit (the receptor for SCF/KL), M-CSF$\mathrm{R}$, and EPO-R, was also observed. The erythroid-affiliated transcription factors GATA-1, NF-E2 (p45 subunit), and erythroid Krüppel-like factor (EKLF) were also all expressed, as was the lymphoid-associated factor ikaros (not shown). Expression of erythroid and granulocytic lineage-specific gene products or effectors, globin, and MPO was also detected, as was expression of the surrogate lymphoid light chain $\lambda 5$ (not shown). Taken together these results support the notion that multiple lineage differentiation programs are simultaneously activated in populations of multipotential cells. The key question then relates to whether the different lineage programs observed coexist within the same, that is, individual, cells or reside in separate and distinct subpopulations of cells. We investigated this issue by analyzing the gene expression programs of individual multipotential cells using single-cell RT-PCR.

\section{Single-cell RT-PCR}

Multiplex single-cell RT-PCR was performed according to the strategy outlined in Figure 1B. The single-cell RTPCR method was first tested by analyzing the expression of the erythroid-affiliated transcription factor GATA-1 in the GATA-1-expressing, erythroid cell line murine erythroleukemia cell line (MEL) (Tsai et al. 1989) as well as in the nonerythroid, myelomonocytic cell line WEHI3B D+ (Warner et al. 1969) that served as a negative control (Fig. 1C). Amplification of housekeeping HPRT transcripts was used as a control for the success of the RTPCR reaction. The frequency of HPRT amplification in both cell types was relatively high: $84 \%$ in MEL and $85 \%$ in WEHI 3B D+. Apart from failure of the RT or PCR reactions, the absence of an HPRT product can also arise from errors in sorting, that is, the failure to deposit a cell or the deposition of a dead cell. Only wells in which HPRT was successfully amplified were considered to be informative.

GATA-1 expression represented by the single 211-bp cDNA product was detected in most of the HPRT-positive MEL cells but not in HPRT-positive WEHI-3B D+ cells. The absence of GATA-1 cDNA products in WEHI $3 \mathrm{~B} D+$ was further confirmed by Southern blotting using full-length GATA-1 cDNA as a probe; although no 211bp GATA-1 derived cDNA products were detected, a larger GATA-1 derived band of $650 \mathrm{bp}$ was observed in some of the reactions. This larger product derives from amplification of endogenous GATA-1 genomic DNA and is also seen in MEL cell reactions where no GATA-1 cDNA products are observed (Fig. 1C). These results suggest that the RT-PCR strategy used here is sufficiently sensitive, specific, and efficient for the multiplex analysis of gene expression at the single-cell level.

Cellular basis of gene expression programs in FDCP-mix $A 4$

FDCP-mix A4 cells undergoing self-renewal in the pres- 
Figure 1. RT-PCR analysis. (A) Analysis of gene expression in a self-renewing population of FDCP-mix A4. Approximately $100 \mathrm{ng}$ of total cellular RNA was used in each reaction; oligo(dT) was used for cDNA synthesis. Marker VI is commercially available (Boehringer Mannheim) and produces the following molecular weight fragments: $2176 / 1766 / 1230 / 1033 / 653 / 517 / 453 / 394 /$ $2 \times 298 / 2 \times 234 / 220 / 2 \times 154$ bp. $(B)$ Strategy for single-cell RT-PCR. Individual cells are flow sorted or micromanipulated into 96 -well arrays of $0.2-\mathrm{ml}$ microamp tubes containing cell lysis buffer. The accuracy of flow sorting was confirmed by microscopic inspection of the number of cells per well deposited into 96-well plates. Reverse transcription is then performed using genespecific primers for all the genes (a,b,c, etc.) of interest. First-round PCR is subsequently performed in the same tubes using these same $3^{\prime}$ gene-specific primers as reverse primers and gene-specific forward primers selected such that forward and reverse primers span at least one intron. Aliquots of this first-round PCR reaction are then replica-plated and second-round PCR reactions performed separately for each gene with fully nested primer pairs. Aliquots of these second-round reactions are visualized by ethidium bromide staining after agarose gel electrophoresis. (C) GATA-1 expression in MEL and WEHI-3B D+. Ninety-six-well arrays of MEL or WEHI 3B D+ were coanalyzed for HPRT (left) and GATA-1 (right) expression. Alphanumeric coordinates identify the well position in the 96-well array from which the electrophoresed products derive. (M) Tracks containing the molecular weight marker (marker IV). Position Al was used for alignment of the sorter. Positions A2-A4 contain no cells and serve as negative controls. Positions H9-H12 contain 10 cells each. The remaining positions contain single cells. The HPRT cDNA-derived PCR product is $247 \mathrm{bp}$ and the GATA-1 cDNA derived product is $211 \mathrm{bp}$. The 650 -bp product seen in some of the GATA-1 tracks results from amplification of the GATA-1 gene; because GATA-1 is on the $\mathrm{X}$-chromosome in the mouse this gene is present at one or two copies per cell depending on the gender of the animal from which the cells derive. Because these genomic products derive from so few copies they are not efficiently amplified and normally can be amplified only if there has been a failure to amplify a cDNA-derived band. Also, genomic bands are seen only if the product is of a sufficiently small size to be suitable for highly efficient amplification. Thus in the case of genes like HPRT where the introns being spanned are relatively large, genomic bands are never seen regardless of the amplification status of the cDNA-derived products. Because no GATA-1 cDNA-derived signals were seen in WEHI-3B D+ cells, the gel was Southern blotted and probed with a radiolabeled GATA-1 probe; only GATA-1 genomic-derived products $(650 \mathrm{bp})$ were observed. In general we have regarded only HPRT-positive wells as informative but it should be noted that on rare occasions wells that score negative for HPRT cDNA score positive for GATA-1 cDNA (cf. HPRT and GATA-1 positions D2 in C). Discrepancies of this nature occur at the $1 \%-2 \%$ level and thus caution should be exercised in interpreting cellular phenotypes that occur with this frequency.

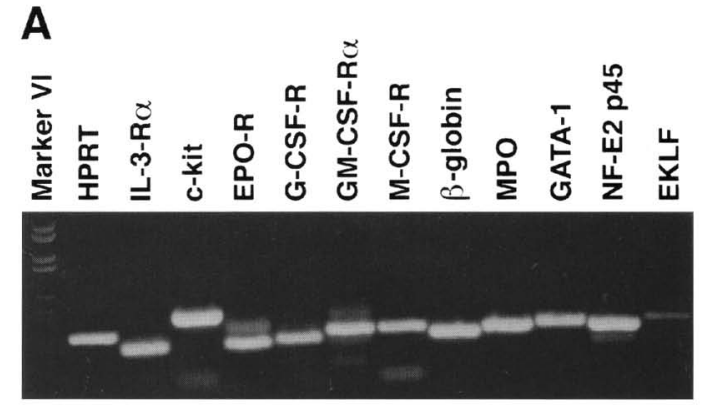

B

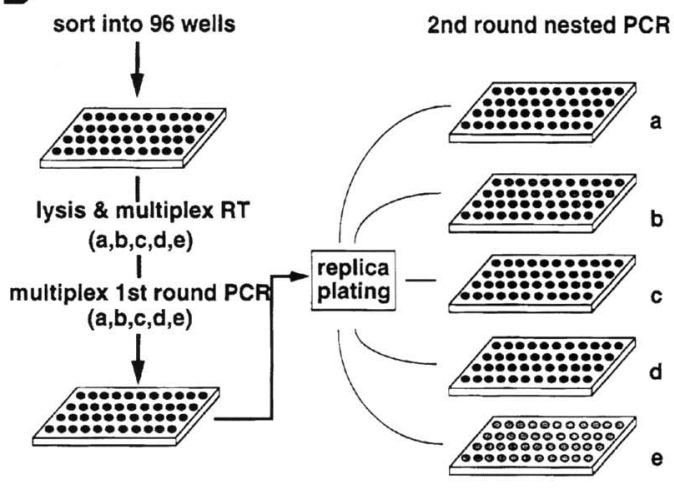

C

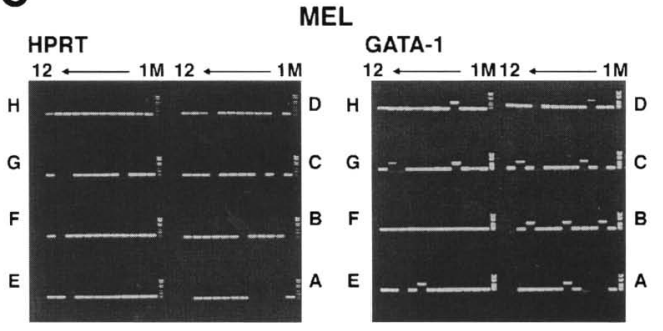

WEHI-3B D+

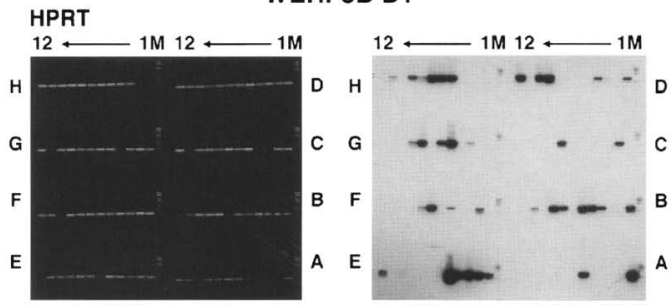

ence of IL-3 were sorted as single cells into two separate 96-well arrays of micro-PCR tubes. Plate I was analyzed for the expression of HPRT, c-kit, EPO-R, G-CSF-R, GATA-1, $\beta$-globin, and MPO (Fig. 2). Plate 2 was also analyzed for expression of HPRT, c-kit, EPO-R, and GCSF-R; in addition the expression of IL-3-R, GM-CSF-R, and M-CSF-R was assessed (Fig. 3). The success of the RT-PCR reactions in both plates was relatively good as judged by amplification of HPRT derived gene products; 75 out of 81 reactions scored positive in plate 1 , and 87 of 88 reactions scored positive in plate 2 . Two main points emerge from the data (Table 1): First, the RT-PCR method produces highly reproducible results; compare plates 1 and 2 for c-kit (41\% vs. 44\%), G-CSF-R (55\% vs.
$54 \%$ ), and EPO-R ( $8 \%$ vs $10 \%$ ) positivity. Second, not all the genes analyzed are expressed in all of the cells analyzed, that is, at the level of individual cells there is considerable heterogeneity in the gene expression programs resident in the multipotential compartment (Figs. 2 and 3$)$.

\section{Coactivation of erythroid and myeloid programs}

Analysis of globin and MPO gene expression in FDCPmix A4 at the single-cell level shows that $67 \%$ of cells express $\beta$-globin and $61 \%$ express MPO (Fig 2); from the composite profile it can be seen that $37 \%$ of cells actually coexpress globin and MPO (in experiments with dif- 


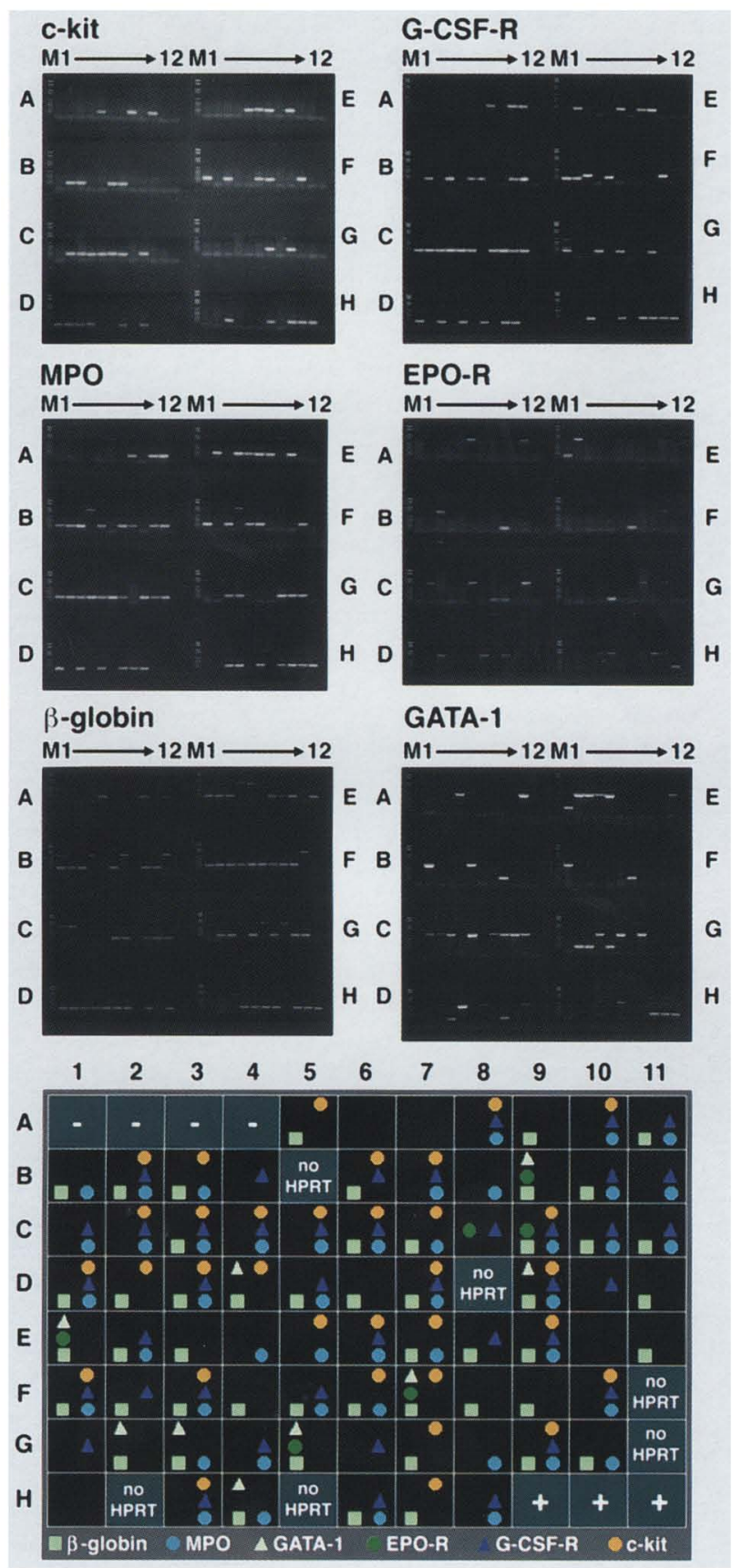

ferent passages of FDCP-mix cells up to $60 \%$ coexpression of globin and MPO has been observed). These results provide direct evidence that individual multipotential cells prime more than one lineage-affiliated program of gene expression prior to exculsive commitment and differentiation to a single hemopoietic lineage. A priori, one might have expected priming/expression of the $\beta$-globin gene to be dependent on, or associated with, the expression of the erythoid-affiliated transcription factor GATA-1, which has been shown to be a key regulator of $\beta$-globin LCRs, promoters, and en-
Figure 2. Analysis of lineage-affiliated gene expression in single FDCP-mix A4 cells. FDCP-mix A4 cells were flowsorted into a 96-well array of microtubes essentially as described in Fig. 1. In this case, positions A1-A4 contain no cells, positions $\mathrm{H} 9-\mathrm{H} 12$ contain 10 cells each, and the remaining positions contain single cells. The first- and second-round primer pairs used for the genes indicated are listed in Materials and Methods. The faint and slightly diffuse fast-running bands seen in some of the gels derive from residual primers. The cDNAderived (RNA) and genomic-derived (DNA) product sizes for the genes investigated are as follows: (c-kit) RNA, $252 \mathrm{bp}$; DNA, not determined (N.D.); (G-CSF-R) RNA, 213 bp; DNA, >1000 bp; (MPO) RNA, 272 bp; DNA, >1200 bp; (EPO-R) RNA, 178 bp, DNA, >900 bp; ( $\beta$-globin) RNA, 224 bp; DNA >700 bp; (GATA1) RNA, 211 bp; DNA, 650 bp; (HPRT) RNA, 247 bp; DNA, N.D. Note that in the G-CSF-R analysis a slightly larger than predicted cDNA-derived band is occasionally observed (position F3); this derives from alternative splicing, which has been reported for this receptor and was confirmed in this instance by DNA sequencing of the PCR product (data not shown).

hancers. Similar arguments apply to the expression of EPO-R. And, consistent with this notion, both GATA-1 and EPO-R expression have been documented in multipotential stem-cell populations in which the $\beta$-globin locus is structurally primed and expressed at low level. Somewhat surprisingly, this predicted association between globin, GATA-1, and EPO-R expression is not consistently observed in our studies. Thus, although the majority of cells $(67 \%)$ are positive for globin expression, less express GATA (12\%) or EPO-R (8\%). An examination of the cellular basis of this expression reveals that all of the GATA-1-expressing cells also express globin and the majority (5 out of 6 ) of the EPO-R positive cells are also globin-positive. Four out of six of the EPO-Rpositive cells express both GATA-1 and globin and these cells do not express MPO; these may well represent cells exclusively committed to the erythroid lineage.

Additional studies on the cellular distribution of cytokine receptor expression in FDCP-mix A4 cells are shown in Figure 3. Consistent with the IL-3 dependence of FDCP-mix A4, nearly all of the cells analyzed express the $\alpha$-chain of the IL-3 receptor. Expression of all the other receptors analyzed was more variable: EPO-R (10\%), G-CSF-R (54\%), c-kit (41\%), GM-CSF-R (48\%), and M-CSF-R $(22 \%)$. Although a high degree of heterogeneity appears to exist between individual A4 cells in terms of receptor expression (even at this high level of sensitivity of detection) the majority of cells coexpress several receptors.

Taken together the results obtained suggest a high degree of plasticity in expression of lineage-affiliated genes in FDCP-mix A4. To confirm that these observations were not an artifact of the RT-PCR method used, and did not result from deregulated gene expression in FDCPmix A4, we performed the additional controls presented in Figures 4 and 5. We first examined globin and MPO expression in single erythroid (MEL)- and myeloid (WEHI 


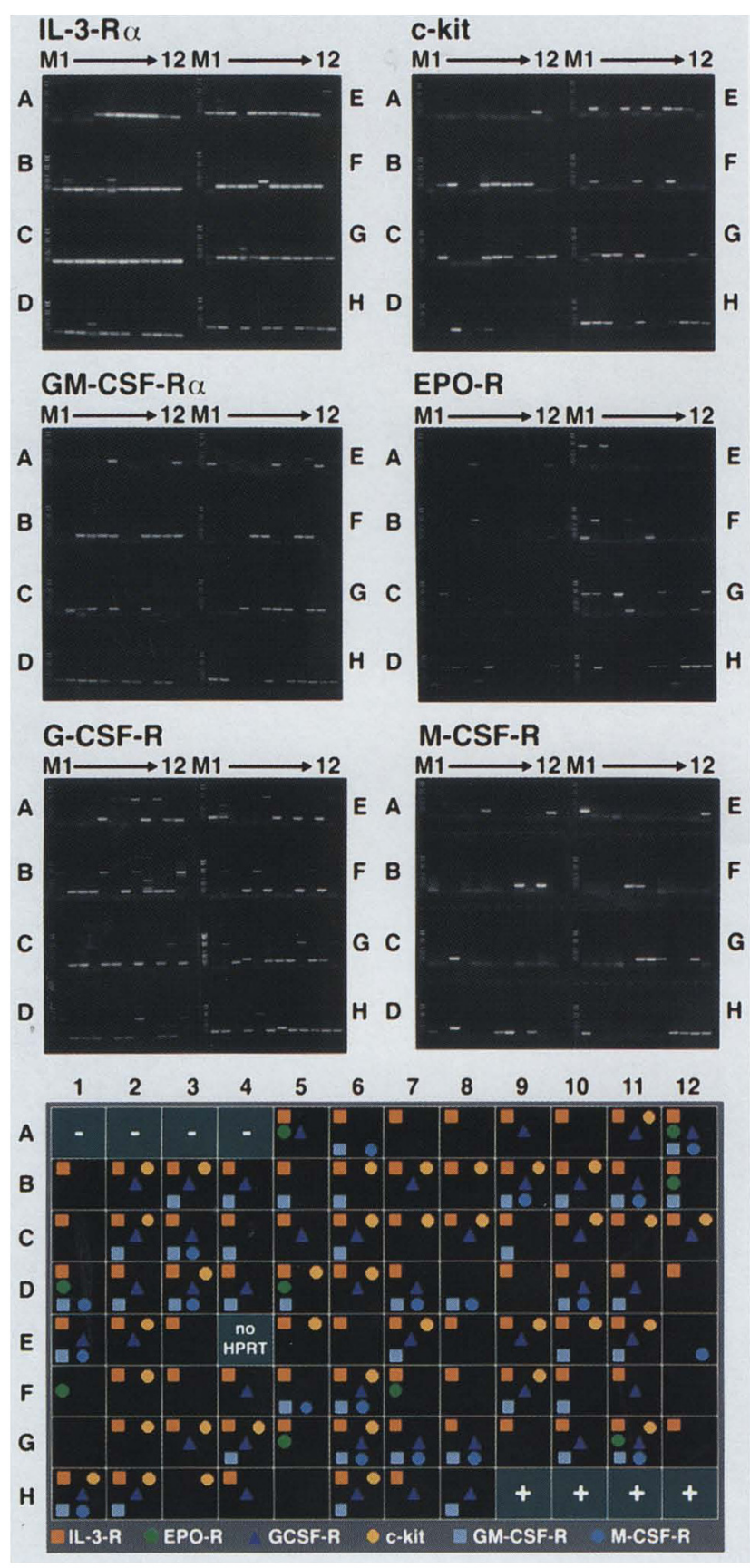

Figure 3. Analysis of cytokine receptor expression in FDCPmix A4. The analysis was carried out exactly as described in Fig. 4. The additional primer sets used generate the following product sizes: (IL-3-R $\alpha$-chain) RNA, 207 bp; DNA >1200 bp; (GMCSF-R $\alpha$-chain) RNA, 250 bp; DNA, N.D.; (M-CSF-R) RNA, 242 bp; DNA, N.D. cDNA products derived from alternatively spliced G-CSF-R mRNAs are seen as before. Similarly derived products are also seen in the GM-CSF-R analysis.

3B D+)-committed progenitor cells; MEL cells express globin but not MPO (Fig. 4A) and WEHI 3B D+ cells express MPO and, with the exception of one reaction, do not express globin (Fig. 4B). These results were con- firmed by RT-PCR analysis of RNA derived from populations of MEL, WEHI-3B D+, and FDCP-mix A4 (Fig. 4C). Thus coexpression of globin and MPO in FDCP-mix A4 is not an RT-PCR artifact but represents an authentic gene expression program in these cells. Similarly, multilineage coexpression of cytokine receptors seen in primitive cells like FDCP-mix A4 is not observed in more diferentiated cells like MEL and WEHI-3B D+; EPO-R and G-CSF-R expression is restricted to MEL and WEHI-3B D+ cells, respectively.

To exclude the possibility that the coexpression profiles we observed were not the result of trivial or deregulated gene expression in FDCP-mix A4 we analyzed these cells for expression of nonhemopoietic-related genes. FDCP-mix A4 cells do not express epidermal (EGF receptor) or muscle (desmin, myogenin) associated genes, either at the single-cell (Fig. 5, A,B) or the population levels (Fig. 4C; data not shown).

\section{Receptor expression correlates with growth factor-dependent cell survival}

In contrast to the expression of globin and MPO, the expression of transcription factors and cytokine receptors is likely to have direct biological consequences for multipotential cells if the low level of transcription detected by RT-PCR is translated into functional protein. Previous reports have documented low levels of GATA-1 transcription in populations of FDCP-mix A4 cells by Northern blot analysis (Crotta et al. 1990; Heberlein et al. 1992), and electromobility shift assays suggest that at least some of this transcription results in the production of functional GATA-1 protein. However, we were unable to detect GATA-1 protein in FDCP-mix A4 cells by immunostaining with anti-GATA-1 antibodies /data not shown|, suggesting that protein levels within the GATA1 -expressing cells are relatively low. Expression of cytokine receptors is also low; this is evident from Northern blot analyses and also from experiments attempting to detect receptor proteins using labeled ligands or antireceptor antibodies (Nicola and Metcalf 1988, McKinstry

Table 1. Gene expression in individual FDCP-mix A4 cells

\begin{tabular}{lcc}
\hline Genes & ${\text { Plate } 1^{\mathrm{a}}}^{\mathrm{a}}$ & Plate $2^{\mathrm{a}}$ \\
\hline HPRT & $75 / 81$ & $87 / 88$ \\
& $100 \%$ & $100 \%$ \\
IL-3-R $\alpha$ & - & $91 \%$ \\
c-kit & $44 \%$ & $41 \%$ \\
EPO-R & $8 \%$ & $10 \%$ \\
G-CSF-R & $55 \%$ & $54 \%$ \\
M-CSF-R & - & $22 \%$ \\
GM-CSF-R $\alpha$ & - & $48 \%$ \\
MPO & $61 \%$ & - \\
$\beta$-globin & $67 \%$ & - \\
GATA-1 & $12 \%$ & - \\
\hline
\end{tabular}

Gene expression $(\%)$.

a (-) Not done. 

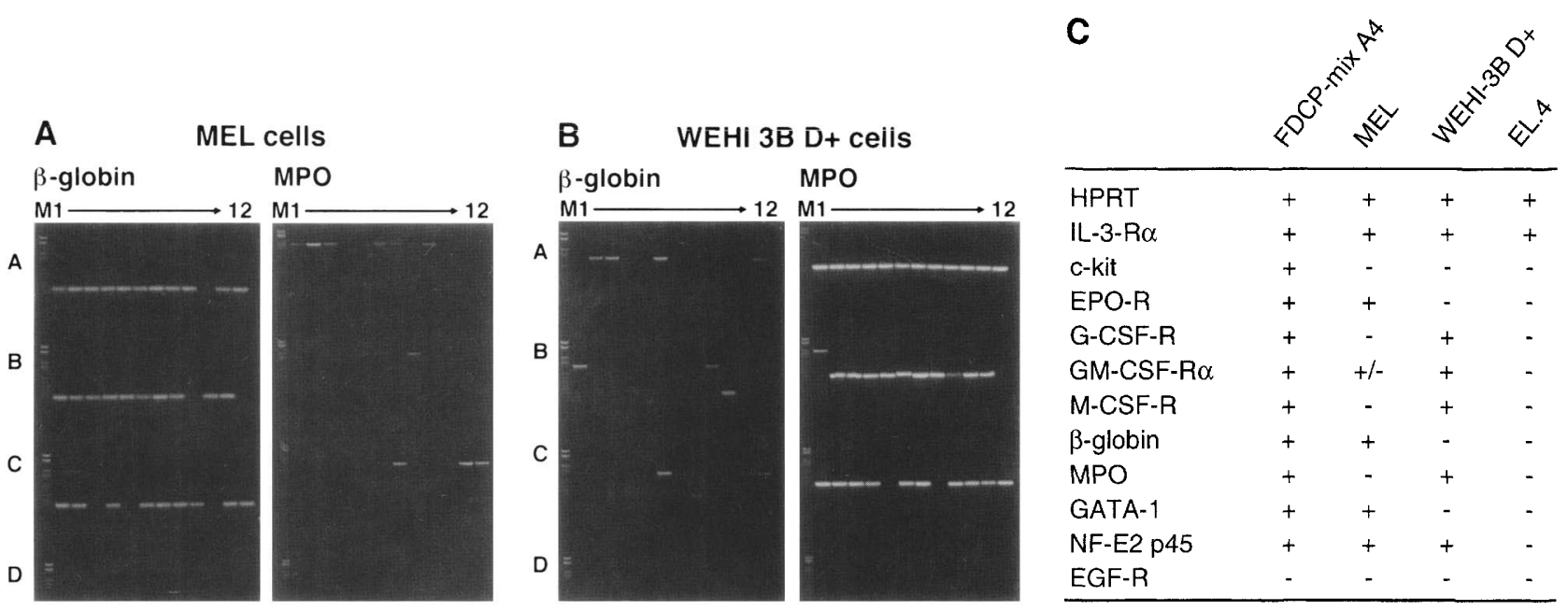

Figure 4. Selectivity of gene expression programs in multipotential cells. $(A, B)$ Analysis of globin and MPO expression in individual erythroid-committed MEL cells $(A)$ and myeloid-committed WEHI 3B D+ cells $(B)$. $(C)$ Analysis of gene expression by RT-PCR of populations of MEL, WEHI 3B D+, FDCP-mix A4, and control EL-4 (pre-T lymphocytic) cells.

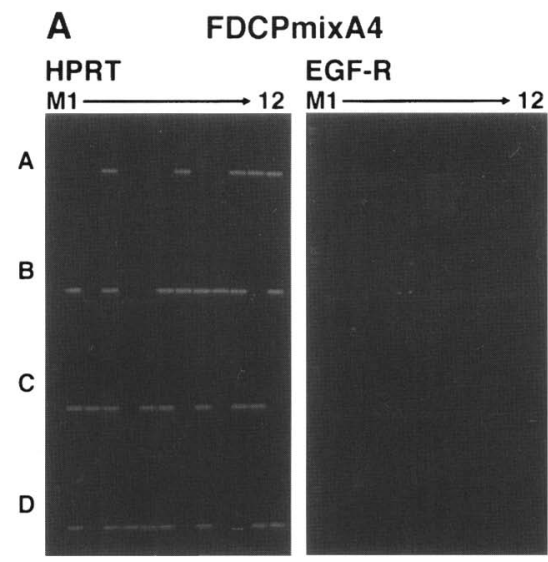

B

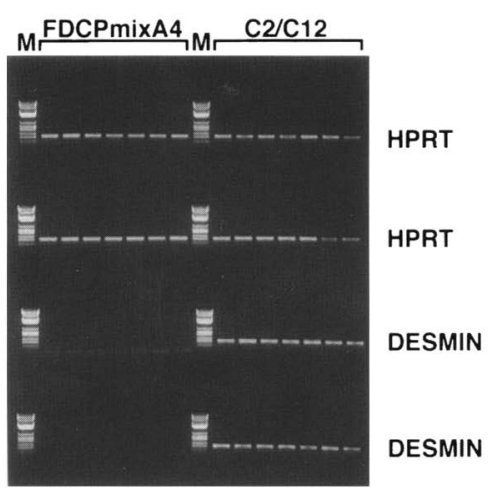

Figure 5. Analysis of nonhemopoietic gene expression in FDCP-mix A4. (A) EGF receptor expression in FDCP-mix A4; the sensitivity of the primers was confirmed in control experiments with single EGF-R-expressing NIH-3T3 cells (not shown). (B) Analysis of desmin expression in individual FDCP-mix A4 and control $\mathrm{C} 2 / \mathrm{C} 12$ myoblasts. Similar results to those shown here for desmin were obtained in an analysis of myogenin expression by FDCP-mix A4 and C2/C12 cells (not shown). et al. 1997). Using radiolabeled growth factors in binding assays on FDCP-mix cells it is possible to detect lowlevel expression of receptors for GM-CSF and G-CSF, but not for EPO (Heyworth et al. 1991, 1995; A.M. O'Farell and C.M. Heyworth, unpubl.).

Although informative, detection of receptor proteins does not necessarily represent a gold standard when considering the receptor biology of stem cells because biological responses to cytokines have been documented in cells in which receptor proteins were present at levels below detection. For this reason we turned to functional assays, measuring the response of single cells to specific growth factors. Single-cell RT-PCR analysis was performed on a different passage of FDCP-mix A4 cells with results similar to those already presented (see Table 2). The expression of functional receptor was assessed in a short-term survival assay. In the absence of IL-3, A4 cells initiate an apoptotic program within 6-8 hr and die within $20 \mathrm{hr}$. The anti-apoptotic function of IL-3 in this context can be delivered by alternative growth factors if the cells express the appropriate receptors. For example, $21 \%$ of cells can be protected from apoptosis, in the short term, by stem cell factor (SCF) (Table 2). After a 20-hr incubation period the percentages of the cells rescued by IL-3, EPO, and G-CSF correlated well with the percentages of receptor gene expression scored by single-cell RT-PCR (Table 2).

GM-CSF- and M-CSF-mediated survival was assessed in a further series of three independent duplicate experiments using another passage of FDCP-mix A4 cells. Control experiments using SCF gave a mean survival value of $17.3 \%$ (S.E.M. 5.5\%). GM-CSF-dependent singlecell survival was in the range expected based on the previous PCR results (mean $24 \%$, s.E.M. $1.9 \%$ ). In contrast M-CSF-dependent survival was very low (mean $1.9 \%$, S.E.M. $0.99 \%$ ). This apparent failure of cells to respond to M-CSF in a short-term survival assay is consistent with the fact that unlike other cytokines (e.g., IL-3, EPO, G- 
Table 2. Receptor detection by RT-PCR correlates with receptor-mediated survival

\begin{tabular}{lccc}
\hline Genes & Plate $1^{\mathrm{a}}$ & Plate $2^{\mathrm{a}}$ & $\begin{array}{c}\text { Percent survival } \\
(n=600)\end{array}$ \\
\hline HPRT & $83 / 88$ & $87 / 88$ & \\
& $100 \%$ & $100 \%$ & $92 \pm 3$ \\
IL-3-R $\alpha$ & - & $89 \%$ & $21 \pm 7$ \\
c-kit & - & - & $9 \pm 7$ \\
EPO-R & $6 \%$ & $3 \%$ & $29 \pm 4$ \\
G-CSF-R & $37 \%$ & $33 \%$ & - \\
M-CSF-R & - & $14 \%$ & - \\
GM-CSF-R $\alpha$ & - & $32 \%$ & - \\
MPO & $76 \%$ & - & - \\
$\beta$-globin & $80 \%$ & - & - \\
GATA-1 & $34 \%$ & - & - \\
\hline
\end{tabular}

Single FDCP-mix A4 cells were sorted into 96-well plates. Plates 1 and 2 were analyzed by single-cell RT-PCR, and the percentage of cells positive for each gene analyzed were recorded. Cells in the other plates were incubated in the presence of the factors indicated (see Materials and Methods for details), and the number of cells surviving after $20 \mathrm{hr}$ were recorded; a total of 2880 cells were scored in each experiment. a(-) Not done.

CSF, and TPO/ M-CSF has not been reported to act as a survival factor for multipotent cells.

Because antibodies to $\mathrm{c}$-kit are readily available and suitable for fluorescence-activated cell sorting we were able to further examine the relationship between the expression of c-kit protein at the cell surface /as judged by FACS) and SCF-mediated cell survival. Twenty-five percent of the A4 cell population studied reacted positively with an anti-c-kit monoclonal antibody and, strikingly, $26 \%$ of this same population could be protected from apoptosis by SCF in short-term single-cell survival assays. We therefore sorted A4 cells on the basis of their reactivity to the anti-c-kit monoclonal antibody and tested their SCF-responsiveness. c-kit-negative and c-kit-positive cells did not vary in their IL-3 responsiveness; IL-3-mediated short-term survival was $67 \%$ for the c-kit-negative and $73 \%$ for the c-kit-positive cells. As expected, $<1 \%$ of $\mathrm{c}$-kit-negative cells could be rescued from apoptosis by SCF; in contrast, $18 \%$ of the c-kitpositive cells survived under these conditions. Although the responsiveness of the c-kit-positive cells to SCF is significantly different than that of the c-kit negative cells, it is not as high as expected: $25 \%$ of the unsorted population is responsive to SCF, and the responsiveness of a c-kit enriched population might be expected to be $100 \%$ rather than $18 \%$, as observed. The reduced responsiveness of the c-kit receptor in the positively sorted population is presumably a consequence of antibody binding to the receptor resulting in its functional neutralization (McKinstry et al. 1997). Taken together these results are consistent with the notion that the RT-PCR data broadly reflect the expression of functional receptor molecules at the cell surface.

\section{Analysis of primary multipotential hemopoietic cells}

The results obtained in FDCP-mix A4 cells indicate that individual multipotential cells, under the conditions of self-renewal, coactivate multiple lineage programs prior to unilineage commitment. However, FDCP-mix A4 cells have been subjected to continual self-renewal in vitro, and therefore may not be strictly speaking identical to their in vivo multipotential or stem-cell counterparts. Antibodies directed against the stem-cell antigen CD34 are widely used for the identification and purification of human hemopoietic stem and progenitor cells (Greaves et al. 1995). More recently we have shown that murine bone marrow cells sorted on the basis of CD34 expression are capable of reconstituting the hemopoietic systems of lethally irradiated mice; stem-cell activity within the CD34-positive population can be further enriched using standard lineage depletion techniques (Krause et al. 1994; D. Krause, unpubl.). We therefore analyzed these normal multipotential cells for their pattern of gene expression.

$\mathrm{CD}^{4} 4^{+}$, lin $^{-}$murine bone marrow cells were isolated and individually micromanipulated into PCR tubes containing cell lysis buffer. Single-cell RT-PCR analysis was carried out as before and the results are presented in Figure $6 \mathrm{~A}$ and $B$; a summary of these data is presented in Figure $7 \mathrm{~A}$ and $B$, respectively. In addition to the use of HPRT as an RTPCR control, primers against the CD34 messenger were included in one set of reactions; parallel analysis of two sets of cells with the same primer pairs once again suggests a high degree of reproducibility. It can be seen that nearly all the cells (17/18 informative wells) have primed the MPO locus. In addition, a significant fraction of these have also activated a program of $\beta$-globin locus expression (11/ 17). The patterns of GATA-1 and EPO-R expression are also similar to those obtained in the FDCP-mix A4 model system with few cells expressing either molecule. As with A4 cells, the IL-3 receptor appears to be widely expressed on the CD34 ${ }^{+}, \mathrm{lin}^{-}$bone marrow cells. Whereas the expression of IL-3R on A4 may well reflect an in vitro selection for IL-3 dependence, the wide expression on CD34+ cells presumably reflects a genuine in vivo function for IL-3 with regard to normal multipotential cells. The expression of all the remaining cytokine receptors, c-kit, G-CSF-R, GM-CSF-R, and M-CSF-R, appears to occur at a higher frequency than that observed with FDCP-mix A4 with several cells coexpressing most if not all of these receptors; coexpression of G-CSF-R and c-kit is the most frequently observed phenotype (78\% of cells). Cells with this phenotype are also found in the A4 population (29\%). The striking similarity of G-CSF-R/c-kit double positive A4 and $\mathrm{CD}^{2} 4^{+}$, lin $^{-}$cells with respect to their globin and MPO gene expression programs is shown in Table $3 \mathrm{~A}$. The comparison of these two populations with respect to expression of other cytokine receptors (Table $3 \mathrm{~B}$ ) is less striking but still shows considerable similarities.

\section{Discussion}

Lineage promiscuity in multipotential cells

In this study we have examined the transcriptional pro- 


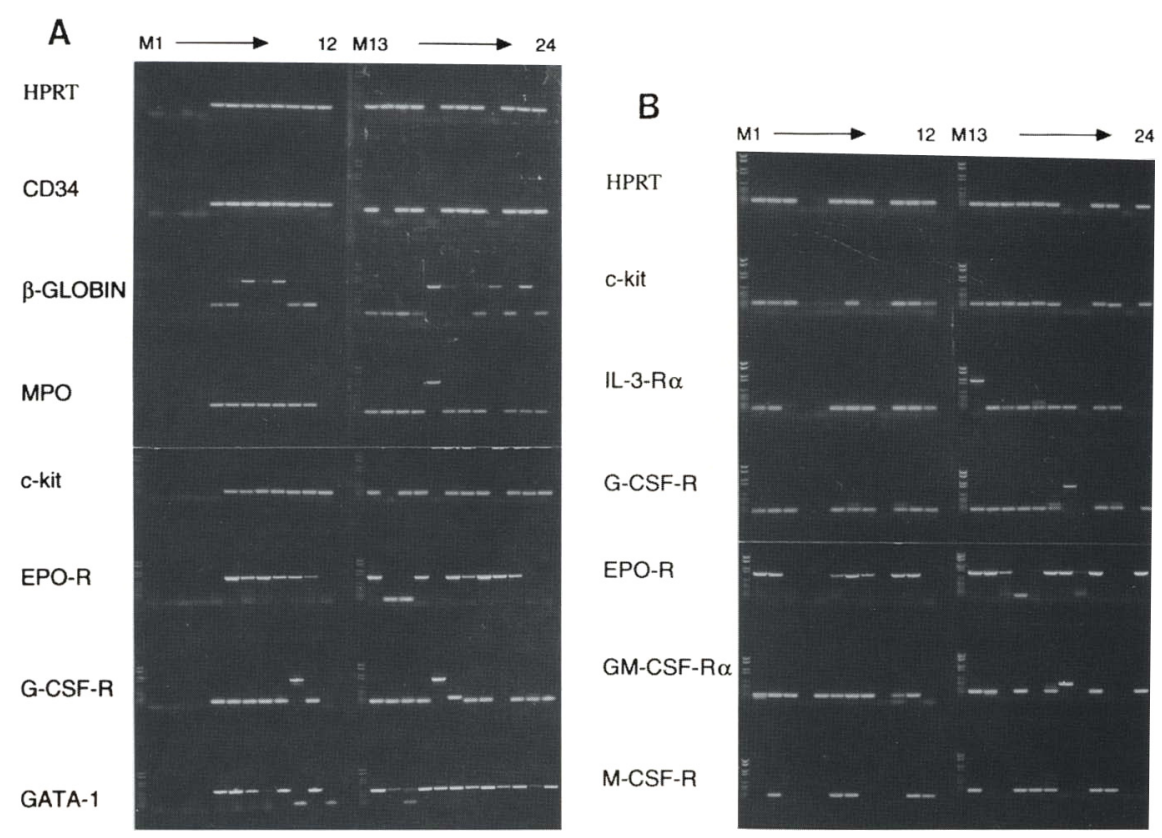

Figure 6. Gene expression in individual $\mathrm{CD} 34^{+}$, lin ${ }^{-}$cells. CD $34^{+}$, lin ${ }^{-}$cells were isolated from murine bone marrow as described in Materials and Methods and micromanipulated individually into $0.2-\mathrm{ml}$ microtubes containing lysis buffer. Multiplex, single-cell RT-PCR analysis was performed as described earlier. (A) Analysis of CD34, c-kit, globin, mpo, GATA-1, EPO$\mathrm{R}$, and G-CSF-R; positions 1-4 do not contain any cells and serve as negative controls, whereas the experimental samples in positions 5-24 contain one cell each. (B) Analysis of IL-3-R, c-kit, EPO-R, G-CSF-R, GM-CSF-R, and M-CSF-R. grams of multipotential hemopoietic cells using singlecell RT-PCR. The results showed that these cells activate a number of distinct lineage-affiliated gene expression programs prior to exclusive lineage commitment and differentiation. In particular, coexpression of globin (erythroid) and myeloperoxidase (granulocytic) genes was observed in several cells. Overall, our results parallel the observations on promiscuous or multilineage gene expression in stem-cell leukemias that in part led to the present hypothesis and experiments (Greaves et al. 1986). These results have important implications for early events in lineage determination but need to be interpreted with caution.

A

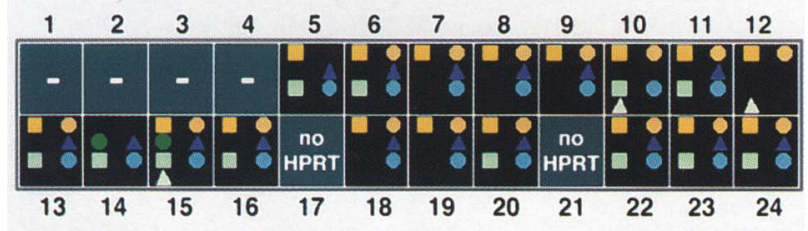

B

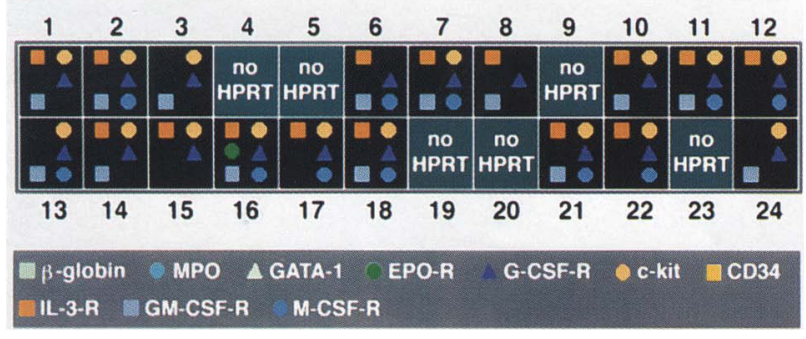

Figure 7. Summary of gene expression programs of individual $\mathrm{CD}^{+} 4^{+}$, lin $^{-}$cells. The data presented in Fig. 6, A and B, are summarized in $A$ and $B$ of this figure, respectively.
First, the expression patterns observed in individual cells could, in theory, be trivial and inconsequential. It has been postulated in the past that all genes are expressed at some low level in all cells; this low level of transcription is detectable by sensitive assays, such as RT-PCR, and termed illegitimate transcription /Chelly

Table 3. Comparison of gene expression in FDCP-mix A4 and $C D 34^{+}$, lin $^{-}$cells

\begin{tabular}{lcc}
\hline Gene expression & FDCP-mix A4 & CD34+, Lin $^{-}$ \\
\hline A. Globin/MPO gene expression program \\
G-CSF-R + c-kit & $22 / 75($ as $100 \%)$ & $14 / 18($ as $100 \%)$ \\
+ -globin & $1(4.5 \%)$ & $0(0 \%)$ \\
+ MPO & $9(41 \%)$ & $6(43 \%)$ \\
+ - 3 -globin + MPO & $11(50 \%)$ & $7(50 \%)$ \\
\hline
\end{tabular}

B. Growth factor receptor expression program

\begin{tabular}{lcc} 
G-CSF-R + c-kit & $25 / 87($ as $100 \%)$ & $16 / 18($ as $100 \%)$ \\
+0 & $10(40 \%)$ & $1(6 \%)$ \\
+ M & $0(0 \%)$ & $3(19 \%)$ \\
+ GM & $9(36 \%)$ & $5(31 \%)$ \\
+ M + GM & $5(20 \%)$ & $6(38 \%)$ \\
+ M + GM + EPO & $1(4 \%)$ & $1(6 \%)$ \\
+ IL-3 & $25(100 \%)$ & $13(81 \%)$ \\
\hline
\end{tabular}

FDCP-mix A4 and CD34+ ${ }^{+}$lin ${ }^{-}$cells were preselected for $\mathrm{G}^{-}$ CSF-R and c-kit receptor expression. This represents $22 / 75$ and $25 / 87$ cells in the FDCP-mix analyses, and 14/18 and 16/18 cells in the CD34 $4^{+}$, lin $^{-}$analyses. The number of cells additionally expressing the characters listed are indicated. These values are also expressed as a percentage (in brackets) of the G-CSF-R/ c-kit double-positive cells (taken as $100 \%$ for this purpose). (IL-3) IL-3-R $\alpha$; (EPO) EPO-R; (M) M-CSF-R; (GM) GM-CSF-R $\alpha$. 
et al. 1989). Two principal lines of reasoning suggest that the low level of transcription we have detected by RTPCR in our studies does not reflect such illegitimate activity. (1) The pattern of gene expression observed is selective or restricted. Coexpression of lineage-affiliated gene expression programs appears to be a feature of multipotential and not unilineage-committed hemopoietic cells. Thus, globin and GATA-1 gene expression was found in erythroid-committed but not myeloid-committed cell lines and MPO expression was detected in myeloid- but not erythroid-committed cells. Furthermore, expression of nonhemopoietic related genes such as epidermal growth factor receptor, myogenin, and desmin was not detected in FDCP-mix A4. (2) The percentage of cells found to be expressing cytokine receptor mRNAs by RT-PCR correlated favorably with the percentage of cells able to respond functionally to corresponding cytokine stimuli.

Second, our data differs from that of two other studies in which dual or multilineage gene expression was not detected in individual progenitor cells (Berardi et al. 1995; Brady et al. 1995, Orlic et al. 1995). In these studies, mRNA expression was assessed using oligo(dT)primed RT-PCR reactions. The differences in results are in part probably attributable to the increased sensitivity afforded by the gene-specific priming approach used in the current study. The discordant data may also reflect variations in the cell studied. Berardi and colleagues examined quiescent, noncycling stem cells that may well exhibit a null phenotype. Brady and colleagues selected for analysis cells whose siblings bred true with regard to lineage output. Such patterns of colony formation are at odds with the random assortment of lineages observed in more primitive blast cell-derived colonies (Suda et al. 1984) and suggest that the cells analyzed by Brady and colleagues are more restricted or differentiated with regard to lineage options and expression.

We have analyzed two cell types: IL-3-dependent progenitor cells derived from long-term marrow cultures (Spooncer et al. 1986) and uncultured marrow cells with the stem-cell phenotype CD34 ${ }^{+}$, lin $^{-}$(Spangrude et al. 1988; Krause et al. 1994; Greaves et al. 1995) sorted directly from bone marrow. The lineage potentialities of individual cells within these populations cannot be known with certainty. However, in our hands very small numbers $(-20)$ of $\mathrm{CD} 34^{+}$, lin ${ }^{-}$cells can reconstitute hemopoiesis in vivo, suggesting that they are multipotential (D. Krause, unpubl.). Whereas, FDCP-mix A4 cells do not function as stem cells in vivo, early passages have CFU-S activity (Spooncer et al. 1986) and FDCP-mix cells as a population are multipotential in vitro. Because their developmental capabilities as single cells are unknown, no direct comparison with the progenitor cells selected for study by Brady and colleagues can be made. These caveats aside, the critical observation is that in two multipotential cell populations, individual cells express diverse patterns of lineage-affiliated genes. This expression is selective and nontrivial and includes dual expression of genes encoding proteins that are functionally associated with alternative cell fates.

\section{Priming versus expression}

Although stressing that the method used in this study is not quantitative, it is clear that the levels of expression of genes encoding lineage-affiliated effector proteins such as globin and MPO in multipotential cells are substantially lower than those seen in mature lineage-committed cells like erythroblasts and promyelocytes; the expression of MPO and globin in FDCP-mix A4 is barely detectable by Northern blot (Ford et al. 1992b; Cross et al. 1994). The expression of these molecules in multipotential cells is presumably a consequence of alterations in the chromatin structure of the globin and MPO loci that occur as a prelude to full-scale transcriptional activation; the accessibility of these regions to the cellular transcriptional machinery underlies the low level of transcription. We have documented some of these chromatin changes at the population level in a variety of multipotential cell lines including FDCP-mix A4. Our results showed that key cis-acting regulatory regions of the $\beta$-globin (Jimenez et al. 1992), MPO (Ford et al. 1996), $\mathrm{IgH}$, and CD3 genes (Ford et al. 1992a) were nucleasehypersensitive, that is, in an accessible conformation; sterile T-cell receptor transcripts were also detected (Ford et al. 1992a). FDCP-mix cells also express the Tcell-associated proteinase inhibitor Serpin 2A (Hampson et al. 1997) and a characteristic T-cell protease, Ganzyme B (Hampson et al. 1992). Granzyme B has been shown recently to be expressed in mobilized CD34-positive cells (Berthou et al. 1995). The fact that we have now documented coexpression of globin and MPO transcripts in individual cells provides strong evidence that different lineage-affiliated gene activation programs have been primed in the same cells rather than in different subpopulations of cells. The coexpression of cytokine receptors by individual multipotential cells is also consistent with this view, though, interestingly, cells with ostensibly similar equivalent lineage potentials as revealed by globin and MPO dual-expression have variable receptor expression profiles, reminiscent of functional data on the random assortment of lineages within individual differentiating blast cell colonies (Suda et al. 1984). Understanding the biological consequences of receptor expression in multipotential cells, however, is compounded by both the functional overlap that exists between different cytokine receptors and the multifunctionality of individual receptors themselves.

\section{Molecular mechanisms of multilineage priming}

How is multilineage priming achieved at a mechanistic level? If lineage-specific factors such as GATA-1 play a role in priming these loci in multipotential, that is uncommitted, cells then the presence of these factors would also be expected in multipotential cells. If expressed, it would follow that their expression is also promiscuous and, although compatible with simultaneous priming of different lineage-affiliated genes, is insufficient, at least at the level expressed, to precipitate a lineage commitment decision. Alternatively, the initial ac- 
tivation of priming of lineage-specific genes such as globin and MPO may be achieved by noncommittal factors. Lineage commitment and subsequent full-scale transcriptional activation of these loci would then result from expression or functional activation of lineage-affiliated factors that would consolidate or substitute the function of the original priming factors. Recent analysis of the murine MPO enhancer has implicated a critical role for the CEBP-family of transcription factors with temporal exchange of occupancy of CEBP-isoforms $\langle\alpha$ to $\beta, \delta /$ at the MPO enhancer mediating the transition from a primed state in multipotential cells to a transcriptionally active configuration in promyelocytes (Ford et al. 1996). It is interesting to speculate that similar mechanisms may be involved in the priming and subsequent activation of the globin locus, with GATA-2 rather than GATA-1 being involved in the early stages of globin locus priming; GATA-2 is expressed in multipotential cells and is required for the elaboration of this compartment (Tsai et al. 1994; Orlic et al. 1995).

When considering mechanisms for multilineage priming it is important to remember that the profiles we have compiled represent a static snapshot of what may well be a highly dynamic situation in vivo, with cells modulating gene expression programs as a result of cell cycling or changes in microenvironment. Thus, the lineage promiscuity we have observed may reflect simultaneous priming of different lineage-affiliated loci in a single cell (Fig. 8A) or instead reflect the persistence of transcripts produced during temporally discrete transcriptional epi-

A
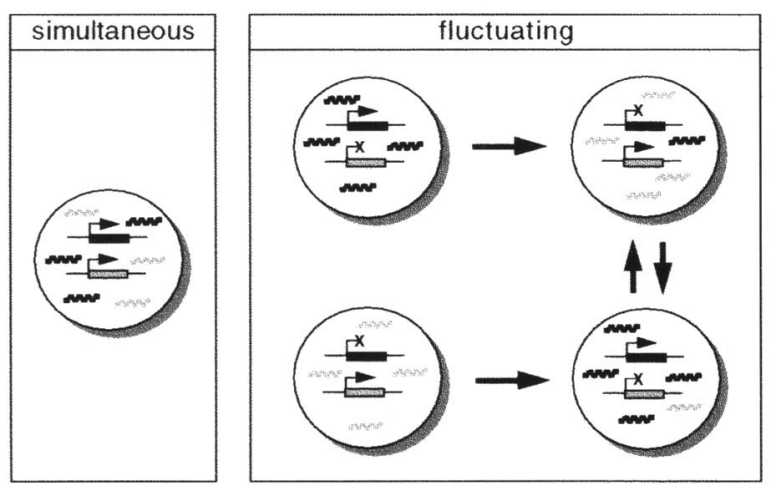

Figure 8. Temporal aspects of lineage promiscuity. Solid and shaded boxes represent genes whose mRNAs (wavy lines) are characteristic of different lineages; arrows and crosses representing on and off states, respectively. $(A)$ A single cell simultaneously primes two different lineage-affiliated programs of gene expression. $(B)$ Cells fluctuate between different programs of gene expression either randomly or in a manner dependent on cycling or microenvironmental cues. Initially program 1 (solid) is on and program 2 (shaded) is off. A switch in programs results in activation of program 2 and silencing of program 1 ; residual mRNA from the previous phase of program 1 expression may persist in the cell. Other cells may initiate program 2 and switch to program 1, and indeed cells that have switched in one direction may switch back. sodes in a cell that is promiscuously transiting through different lineage programs (Fig. 8B). In reality both mechanisms may be at play. The issue of whether two genes are expressed simultaneously has been addressed in the globin locus in red cells through analysis of shortlived intron-derived RNA by fluorescence in situ hybridization (FISH) (Wijgerde et al. 1995). However, the levels of expression of these genes in stem cells are such that this sort of approach is unlikely to succeed. Thus, whether lineage promiscuity in multipotential cells has its basis in simultaneous or fluctuating gene expression will presumably require the development of sensitive assays for interrogating stem cells in real time.

\section{Materials and methods}

Culture of FDCP-mix cells

FDCP-mix cells were derived from long-term bone marrow cultures and were maintained in Iscove's medium supplemented with horse serum (20\% vol/vol) and IL-3 (Spooncer et al. 1986). The source of IL-3 was conditioned medium from a myeloma cell line transfected with the murine IL-3 gene used at $2 \%$ (vol/ voll.

\section{Assessment of survival of FDCP-mix A4 cells}

Exponentially growing FDCP-mix cells were harvested by centrifugation and washed twice with Iscove's medium. Cells were resuspended in medium at $10^{5}$ cells $/ \mathrm{ml}$. Using a Becton and Dickinson FACS Vantage ACDU (automatic cell dispersal unit), single cells were sorted into single round-bottomed wells $196-$ well plates supplied by Falcon). One hundred milliliters of culture medium, containing fetal calf serum $(20 \% \mathrm{vol} / \mathrm{vol})$, Iscove's medium, and the appropriate growth factor, had been added previously to the wells. The wells were assessed using a microscope to check that there was only one cell per well. A total of 2880 wells were scored; no well was found to contain more than one cell immediately after sorting. The wells were incubated at $37^{\circ} \mathrm{C}$ for $20 \mathrm{hr}$ in $5 \% \mathrm{CO}_{2} / 5 \% \mathrm{O}_{2}$ in $90 \% \mathrm{~N}_{2}$. After this period the wells were rescored to check for cell survival.

\section{Recombinant growth factors}

The growth factors used in these studies were all recombinant proteins. Murine IL-3 was supplied by R and D systems (Abingdon, UK) (sp. act. $4 \times 10^{7} \mathrm{U} / \mathrm{mg}$; rat SCF was kindly donated by Amgen; human G-CSF was supplied by Amgen (sp. act. $10^{8}$ $\mathrm{U} / \mathrm{mg}$ ); and human EPO was supplied by Boehringer Mannheim (Germany) (sp. act. $1.2 \times 10^{6} \mathrm{U} / \mathrm{mg}$ ). The growth factors were all used at predetermined optimal concentrations: IL-3, $10 \mathrm{ng} / \mathrm{ml}$; $\mathrm{SCF}, 100 \mathrm{ng} / \mathrm{ml}$; G-CSF, $5000 \mathrm{U} / \mathrm{ml}$; EPO, $5 \mathrm{U} / \mathrm{ml}$.

\section{Purification of $\mathrm{CD} 34^{+}, \mathrm{lin}^{-}$cells}

Bone marrow was obtained from c57BI/6J $\times$ DBA $/ 2$ J F1 mice by dissecting femoral shafts and plugs were flushed into cold media as described previously (Krause et al. 1994). Mononuclear cells were isolated using Ficoll Hypaque 1077 (Sigma). Cells were stained for immunofluorescence using a cocktail of rat-derived antibodies to lineage-restricted antigens (AA4.1, B220, CD5, Gr1, Mac-1, and Ter 119; from Southern Biotechologyl followed by secondary staining with phyco-erythrin $(\mathrm{PE})$-conjugated goat anti-rat immunoglobulin (Southern Biotechnology). Lineagenegative cells were then collected by FACSorting on an EPICS 
752 flow cytometer (Coulter Electronics, Hialeah, FL). The lineage-negative cells $(-5 \%$ of the mononuclear cells $)$ were then stained for CD34 expression and FACSorted as described previously (Krause et al. 1994).

\section{RT-PCR analysis of total cellular RNA}

Total RNA was extracted from cell pellets containing $\sim 10^{7}$ cells by use of the guanadinium thiocyanate method as described by Chirgwin et al. (1979). RNA concentration was determined by spectrophotometry and RNA integrity was determined by gel electrophoresis and visual inspection of ethidium bromidestained ribosomal bands. For first-strand cDNA synthesis $2 \mu \mathrm{g}$ of RNA were used in the $\mathrm{RT}$ reaction with $1 \mu \mathrm{l}$ of oligo $\langle\mathrm{dT}\rangle_{\mid 12-18\}}$ $(50 \mu \mathrm{g} / \mathrm{ml})$ and water to a total volume of $11 \mu \mathrm{l}$. The mixture was added to $4 \mu \mathrm{l}$ of $5 \times$ first-strand buffer $(250 \mathrm{~mm}$ Tris- $\mathrm{HCl}$ at $\mathrm{pH} 8.3,375 \mathrm{~mm} \mathrm{KCl}, 15 \mathrm{~mm} \mathrm{MgCl}_{2}$ ) (GIBCO-BRL), $2 \mu$ of DTT (100 mM, GIBCO-BRL), $1 \mu \mathrm{l}$ of dNTPs (10 mm, Pharmacia), and $1 \mu \mathrm{l}$ of M-MLV reverse transcriptase (200 units, GIBCO-BRL). The reactions were carried out at $37^{\circ} \mathrm{C}$ for $1 \mathrm{hr}$. One-twentieth of these reactions was used for PCR analysis performed in a buffer containing $15 \mathrm{~mm}$ Tris- $\mathrm{HCl}$ at $\mathrm{pH} 8.8,60 \mathrm{mM} \mathrm{KCl}, 1.5 \mathrm{~mm}$ $\mathrm{MgCl}_{2}, 200 \mathrm{~mm} \mathrm{dNTPs}$, and 1 unit of Taq polymerase. Approximately $12 \mathrm{pm}$ of each gene-specific oligomer was used and 35 cycles of PCR $\left(95^{\circ} \mathrm{C}\right.$ for $1 \mathrm{~min}, 60^{\circ} \mathrm{C}$ for $1 \mathrm{~min}, 72^{\circ} \mathrm{C}$ for $\left.2 \mathrm{~min}\right)$ performed. PCR products were visualized by ethidium bromidestaining of flat-bed agarose gels.

\section{Analysis of single cells by RT-PCR}

Single cells were deposited into 96-well arrays of $0.2 \mathrm{ml}$ microtubes containing $3 \mu \mathrm{l}$ of lysis buffer $[0.4 \%$ NP- $40,10 \mu \mathrm{M} / 1$ of dNTPs, $0.5 \mathrm{U} / \mu \mathrm{l}$ of RNAsin (Promega)]. Plates were spun at $2000 \mathrm{rpm}$ for $3 \mathrm{~min}$ at $4^{\circ} \mathrm{C}$. Pelleted cells were lysed for $15 \mathrm{~min}$ on ice. Cell lysates were reverse-transcribed using one or multiple pairs of gene-specific primers (primer sequences are available on request from tariq@icr.ac.uk), according to the conditions described above. First-round PCR with 35 cycles was performed by the addition of $40 \mu 1$ of pre-mixed PCR buffer and 1.25 units of Taq polymerse $(5 \mathrm{U} / \mu 1)$. One-microliter aliquots of first-round PCR reactions were replica-plated into new PCR tubes for second-round PCR, which was carried out using fully nested gene-specific primers. Aliquots of PCR products were gel electrophoresed and visualized by ethidium bromide staining.

\section{Acknowledgments}

We are grateful to Stella Pearson, Lyn Healy, Derek Davies, and Ian Titley for excellent technical assistance and help with cell sorting. We also acknowledge Michael Collector for assistance with the isolation of $\mathrm{CD}^{+} 4^{+}$, lin $^{-}$cells, William Stratford May for his encouragement and support, and Tony Ford for critical reading of the manuscript. This work was supported by the Leukaemia Research Fund and the Cancer Research Campaign, UK. T.D. is a Gibb Research fellow.

The publication costs of this article were defrayed in part by payment of page charges. This article must therefore be hereby marked "advertisement" in accordance with 18 USC section 1734 solely to indicate this fact.

\section{References}

Berardi, A.C., A. Wang, J.D. Levine, P. Lopez, and D.T. Scadden. 1995. Functional isolation and characterisation of human hematopoietic stem cells. Science 267: 104-108.
Berthou, C., J.P. Marolleau, C. Lafaurie, A. Soulie, L. Dal-Cortivo, J.F. Bourge, M. Benbinana, and M. Sasportes. 1995. Granzyme B and perforin lytic proteins are expressed in CD34+ peripheral blood progenitor cells mobilised by chemotherapy and granulocyte colony stimulating factor. Blood 86: 3500-3506.

Brady, G., F. Billia, J. Knox, T. Hoang, I.R. Kirsch, E. Voura, R.G. Hawley, R. Cumming, M. Buchwald, K. Siminovitch, N. Miyamoto, G. Boehmelt, and N. Iscove. 1995. Analysis of gene expression in a complex differentiation hierarchy by global amplification of cDNA from single cells. Curr. Biol. 5: 909922.

Brown, J., M.F. Greaves, and H.V. Molgaard. 1991. The gene for the stem cell antigen, CD34, is conserved in mouse and expressed in haemopoietic progenitor cell lines, brain and embryonic fibroblasts. Int. Immunol. 3: 175-184.

Caplan, A.I. and C.P. Ordahl. 1978. Irreversible gene repression model for control of development. Science 201: 120-130.

Chelly, J., J.P. Concordet, J.C. Kaplan, and A. Kahn. 1989. Illegitimate transcription: Transcription of any gene in any cell type. Proc. Nat1. Acad. Sci. 86: 2617-2621.

Chirgwin, J.M., A.E. Przybyla, R.J. Macdonald, and W.J. Rutter. 1979. Isolation of biologically active ribonucleic acid from sources enriched in ribonuclease. Biochemistry 18: 5294-5299.

Cross, M.A. and T.M. Dexter. 1991. Growth factors in development, transformation, and tumorigenesis. Cell 64: 271-280.

Cross, M.A., C.M. Heyworth, A.M. Murrell, E.O. Bockamp, T.M. Dexter, and A.R. Green. 1994. Expression of lineage restricted transcription factors precedes lineage specific differentiation in a multipotent haemopoietic progenitor cell line. Oncogene 9: 3013-3016.

Crotta, S., S. Nicolis, A. Ronchi, S. Ottolenghi, L. Ruzzi, Y. Shimada, A.R. Migliaccio, and G. Migliaccio. 1990. Progressive inactivation of the expression of an erythroid transcriptional factor in GM- and G-CSF-dependent myeloid cell lines. Nucleic Acids Res. 18: 6863-6869.

Felsenfeld, G. 1992. Chromatin as an essential part of the transcriptional mechanism. Nature 355: 219-224.

Ford, A.M., C.A. Bennett, L.E. Healy, E. Navarro, E. Spooncer, and M.F. Greaves. 1992a. Immunoglobulin heavy-chain and CD3 8 -chain gene enhancers are DNase I-hypersensitive in hemopoietic progenitor cells. Proc. Natl. Acad. Sci. 89: 3424-3428.

Ford, A.M., L.E. Healy, C.A. Bennett, E. Navarro, E. Spooncer, and M.F. Greaves. 1992b. Multilineage phenotypes of interleukin-3-dependent progenitor cells. Blood 79: 1962-1971.

Ford, A.M., C.A. Bennett, L.E. Healy, M. Towatari, M.F. Greaves, and T. Enver. 1996. Regulation of the myeloperoxidase enhancer binding proteins PU1, CEBP $\alpha, \beta$, and $\delta$ during granulocyte-lineage specification. Proc. Natl. Acad. Sci. 93: 10838-10843.

Greaves, M.F., L.C. Chan, A.J. Furley, S.M. Watt, and H.V. Molgaard. 1986. Lineage promiscuity in hemopoietic differentiation and leukemia. Blood 67: 1-11.

Greaves, M.F., I. Titley, S.M. Colman, H.-J. Buhring, L. Campos, G.L. Castoldi, P. Garrido, G. Gaudeneck, J.-P. Girard, J. Ingles-Esteve, R. Invernizzi, W. Knapp, P.M. Lansdorp, F. Lanza, H. Merle-Beral, C. Parravicini, K. Razak, F. Ruiz-Cabello, T.A. Springer, C.E. Van Der Schoot, and D.R. Sutherland. 1995. CD34 cluster workshop report. In Leukocyte typing $V$ (ed. S. Schlossman), pp. 840-846. Oxford University Press, Oxford, UK.

Greenberger, J.S., M.A. Sakakeeny, R.K. Humphries, C.J. Eaves, and R.J. Eckner. 1983. Demonstration of permanent factordependent multipotential (erythroid/neutrophil/basophil) 
hematopoietic progenitor cell lines. Proc. Natl. Acad. Sci. 80: $2931-2935$.

Hampson, I.N., M.A. Cross, C.M. Heyworth, L. Fairbairn, G.E. Cowling, and T.M. Dexter. 1992. Expression and downregulation of cytotoxic cell protease 1 or Granzyme " $\mathrm{B}$ " transcripts during myeloid differentiation of interleukin-3-dependent murine stem cell lines. Blood 80: 3097-3105.

Hampson, I.N., L. Hampson, N. Pinkoski, M. Cross, C.M. Heyworth, R.C. Bleackley, E. Atkinson, and T.M. Dexter. 1997. Identification of a serpin specifically expressed in multipotent and bipotent hematopoietic progenitor cells and in activated T-cells. Blood 89: 108-118.

Heberlein, C., K.D. Fischer, M. Stoffel, J. Nowock, A. Ford, U. Tessmer, and C. Stocking. 1992. The gene for erythropoietin receptor is expressed in multipotential hematopoietic and embryonal stem cells: Evidence for differentiation stage-specific regulation. Mol. Cell. Biol. 12: 1815-1826.

Heyworth, C.M., T.M. Dexter, O. Kan, and A.D. Whetton. 1990. The role of haemopoietic growth factors in self-renewal and differentiation of IL-3-dependent multipotential stem cells. Growth Factors 2: 197-211.

Heyworth, C.M., J. Hampson, T.M. Dexter, F. Walker, A.W. Burgess, O. Kan, N. Cook, S. Valance, and A.D. Whetton. 1991. Development of multipotential haemopoietic stem cells to neutrophils is associated with increased expression of receptors for granulocyte-macrophage colony stimulating factor: Altered biological responses to GM-CSF during development. Growth Factors 5: 87-98.

Heyworth, C.M., M. Alaudin, M. Cross, L.J. Fairbairn, T.M. Dexter, and A.D. Whetton. 1995. Erythroid development of the FDCP-mix A4 multipotent cell line is governed by the relative concentrations of erythropoietin and interleukin 3 . Br. J. Haem. 91: 15-22.

Jimenez, G., S.D. Griffiths, A.M. Ford, M.F. Greaves, and T. Enver. 1992. Activation of the $\beta$-globin locus control region precedes commitment to the erythroid lineage. Proc. Nat1. Acad. Sci. 89: 10618-10622

Krause, D.S., T. Ito, M.J. Fackler, O.M. Smith, M.I. Collector, S.J. Sharkis, and W.S. May. 1994. Characterization of murine CD34, a marker for hematopoietic progenitor and stem cells. Blood 84: 691-701.

Lajtha, L.G. 1979. Stem cell concepts. Differentiation 14: 23 34.

McKinstry, W.J., C.-L. Li, J.E.J. Rasko, N. Nicola, G. Johnson, and D. Metcalf. 1997. Cytokine receptor expression on hematopoietic stem and progenitor cells. Blood 89: 65-71.

Metcalf, D. 1989. The molecular control of cell division, differentiation, commitment and maturation in haemopoietic cells. Nature 339: $27-30$.

Miyajima, A., A.L. Mui, T. Ogorochi, and K. Sakamaki. 1993. Receptors for granulocyte-macrophage colony-stimulating factor, interleukin-3, and interleukin-5. Blood 82: 19601974

Nicola, N.A. and D. Metcalf. 1988. Binding internalization, and degradation of ${ }^{125} \mathrm{I}$-multipotential colony-stimulating factor (interleukin-3) by FDCP-1 cells. Growth Factors 1: 29-39.

Orlic, D., S. Anderson, I.G. Biesecker, B.P. Sorrentino, and D.M. Bodine. 1995. Pluripotent hematopoietic stem cells contain high levels of mRNA for c-kit, GATA-2, p45 NF-E2, and $\mathrm{c}-\mathrm{myb}$ and low levels or no mRNA for $\mathrm{c}$-fms and the receptors for granulocyte colony-stimulating factor and interleukins 5 and 7. Proc. Nat1. Acad. Sci. 92: 4601-4605.

Palacios, R., H. Karasuyama, and A. Rolink. 1987. Ly1+ PRO-B lymphocyte clones. Phenotype, growth requirements and differentiation in vitro and in vivo. EMBO J. 6: 3687-3693. Spangrude, G.J., S. Heimfeld, and I.L. Weissman. 1988. Purifi- cation and characterization of mouse hematopoietic stem cells. Science 241: 58-62.

Spooncer, E., D. Boettiger, and T.M. Dexter. 1984. Continuous in vitro generation of multipotential stem cell clones from src-infected cultures. Nature 310: 228-230.

Spooncer, E., C.M. Heyworth, A. Dunn, and T.M. Dexter. 1986. Self-renewal and differentiation of interleukin-3-dependent multipotent stem cells are modulated by stromal cells and serum factors. Differentiation 31: 111-118.

Suda, J., T. Suda, and M. Ogawa. 1984. Analysis of differentiation of mouse hemopoietic stem cells in culture by sequential replating of paired progenitors. Blood 64: 393-399.

Tsai, F.Y., G. Keller, F.C. Kuo, M. Weiss, J. Chen, M. Rosenblatt, F.W. Alt, and S.H. Orkin. 1994. An early haemopoietic defect in mice lacking the transcription factor GATA-2. Nature 371: 221-226.

Tsai, S.F., D.I. Martin, L.I. Zon, A.D. D'Andrea, G.G. Wong, and S.H. Orkin. 1989. Cloning of cDNA for the major DNAbinding protein of the erythroid lineage through expression in mammalian cells. Nature 339: 446-451.

Warner, N.L., M.A.S. Moore, and D. Metcalf. 1969. A transplantable myelomonocytic leukaemia in BALB/c mice: Cytology, karyotype muramidase content. I. Nat. Cancer Inst. 43: 1108-1112.

Wijgerde, M., F. Grosveld, and P. Fraser. 1995. Transcription complex stability and chromatin dynamics in vivo. Nature 377: 209-213.

Zhu, J., C.A. Bennett, A.D. MacGregor, M.F. Greaves, G.H. Goodwin, and A.M Ford. 1994. A myeloid-lineage-specific enhancer upstream of the mouse myeloperoxidase (MPO) gene. Leukemia 8: 717-723. 


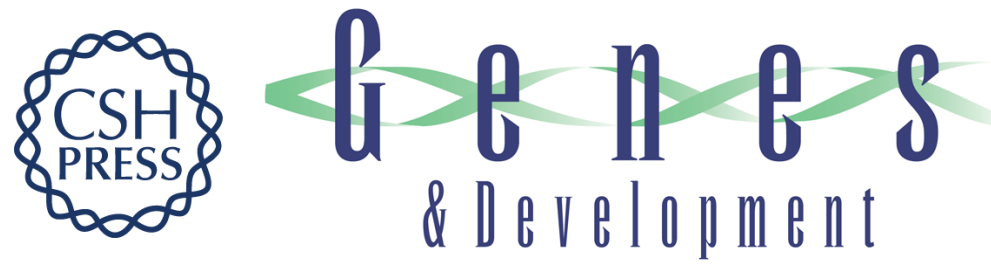

\section{Multilineage gene expression precedes commitment in the hemopoietic system.}

M Hu, D Krause, M Greaves, et al.

Genes Dev. 1997, 11:

Access the most recent version at doi:10.1101/gad.11.6.774

References This article cites 40 articles, 19 of which can be accessed free at: http://genesdev.cshlp.org/content/11/6/774.full.html\#ref-list-1

License

Email Alerting

Service

Receive free email alerts when new articles cite this article - sign up in the box at the top right corner of the article or click here.

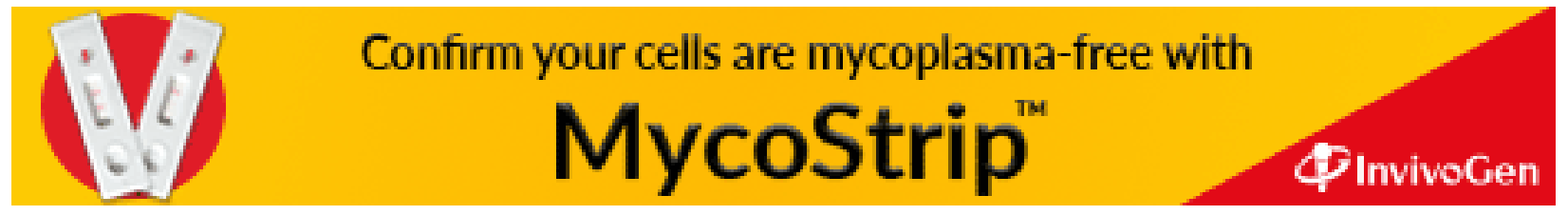

